\title{
ISOLATED DIFFUSE MYOCARDITIS
}

\author{
BY \\ T. PAUL BLANSHARD \\ From the West London Hospital
}

Evans (1949) has described a syndrome having a clinical, cardiographic and pathological pattern that he has named familial cardiomegaly. The following case is reported because it is representative clinically and cardiographically, and yet showed a different pathological picture from that expected.

\section{Report of Case}

A man, aged 20, came under observation at the West London Hospital in June, 1946; he was then 20 years of age. He complained of attacks of giddiness and unconsciousness of short duration, present for eight months. For two months he had had a sharp retrosternal pain accompanied by palpitation on exertion, relieved by rest. There were no other symptoms. He gave a history of rheumatic fever at the age of 7 years, when heart disease was diagnosed. There was a striking family history of heart disease and early death. A maternal great aunt dropped dead in the street at the age of 19. Four aunts and uncles died cardiac deaths between the ages of 23 and $\mathbf{4 0}$ and four others of this line died during infancy of what was said to have been heart disease. Abnormal physical signs were limited to the cardiovascular system. The pulse was irregular from premature beats. The left side of the chest was more prominent than the right. The apex beat was situated in the fifth space one inch outside the midclavicular line. The cardiac impulse was forcible. A presystolic triple rhythm was present, and there was a soft blowing systolic murmur at the apex conducted towards the axilla. The blood pressure was 120/70. There were no basal râles; neither the liver nor spleen was palpable. The central nervous system was normal. X-rays and fluoroscopy demonstrated great enlargement of the heart, particularly of the left ventricle. The electrocardiogram showed ventricular premature beats, tall wide $P$ waves, inversion of $T$ in leads $I$ and II with diphasic $T$ in IV R, and depression of S-T in these leads. The blood count, sedimentation rate, blood cholesterol, and sugar tolerance curve were all normal. There was no fever.

During the next three years he suffered remarkably little disability and led a fairly normal life. There were several attacks late in 1946 of severe substernal pain radiating to the arms accompanied by sweating and vomiting, but not by rise in temperature or sedimentation rate or change in the electrocardiogram. Syncopal attacks occurred irregularly throughout the whole period. The pattern of a left bundle branch block developed. Finally he became dyspnoeic on exertion and coughed up blood on several occasions. A well marked third heart sound, and sometimes a fourth, became audible. Death in June, 1949, was preceded by a prolonged bout of paroxysmal tachycardia (Fig. 1).

\section{Summary of Necropsy}

Heart failure, isolated myocarditis, and bronchopneumonia. The heart weighed $820 \mathrm{~g}$. The pericardium was adherent over the anterior, lateral, and posterior aspects of the left ventricle and also to the diaphragm. The adhesions were tough and vascular at one point. There were $150 \mathrm{ml}$. of fluid in the pericardial sac. The heart was pale, and there were many petechial hæmorrhages. There was a fibrous patch 2.5 by $1.2 \mathrm{~cm}$. in the right ventricle. Both ventricles were enlarged; the left was thick and tough and the right was flabby. The aortic cusps were healthy. The right ventricular wall was $5 \mathrm{~mm}$. thick. At the junction of the upper one-third and lower two-thirds of the organ the septum measured $2.5 \mathrm{~cm}$. in thickness and the left ventricle $2.5 \mathrm{~cm}$. The left ventricular wall was enormously hypertrophied, and fibrous towards the apex anteriorly. The mitral valve was normal, and the left atrium was a little dilated. There was roughening on the margin of the 
mitral valve and patches of atheroma around the right coronary orifice. The coronary arteries were healthy but small compared to the thickening of the left ventricle. There was diffuse fibrosis over the caudal end of the septum and apex, and adhesions over the posterior aspect.

The great vessels showed no abnormality. The lungs were congested with patches of bronchopneumonia. The liver was congested and there was a marked degree of nutmeg appearance. The spleen weighed $370 \mathrm{~g}$. There were no abnormalities elsewhere.

Microscopic examination of the heart. In all parts examined there was dense patchy fibrosis of the myocardium, present also beneath the endocardium; the muscle fibres were hypertrophied. There was a scattered cellular infiltrate consisting of lymphocytes and mononuclear cells (Fig. 2).

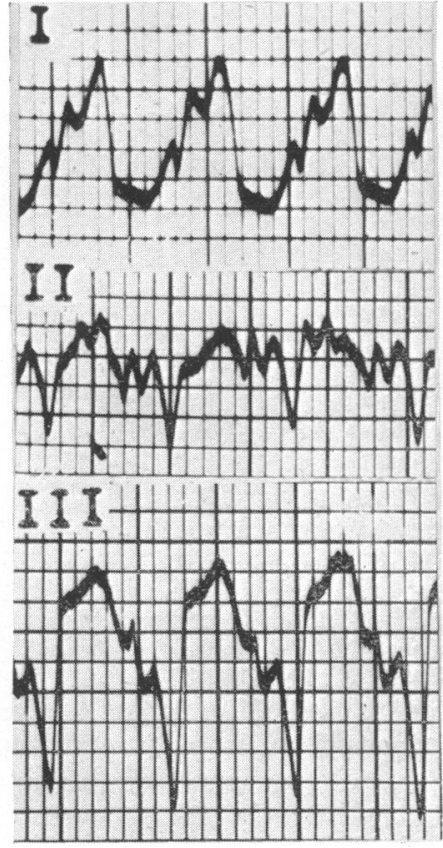

FIG. 1.-Electrocardiogram showing pattern of paroxysmal tachycardia. Time intervals $1 / 5$ and $1 / 25$ second.

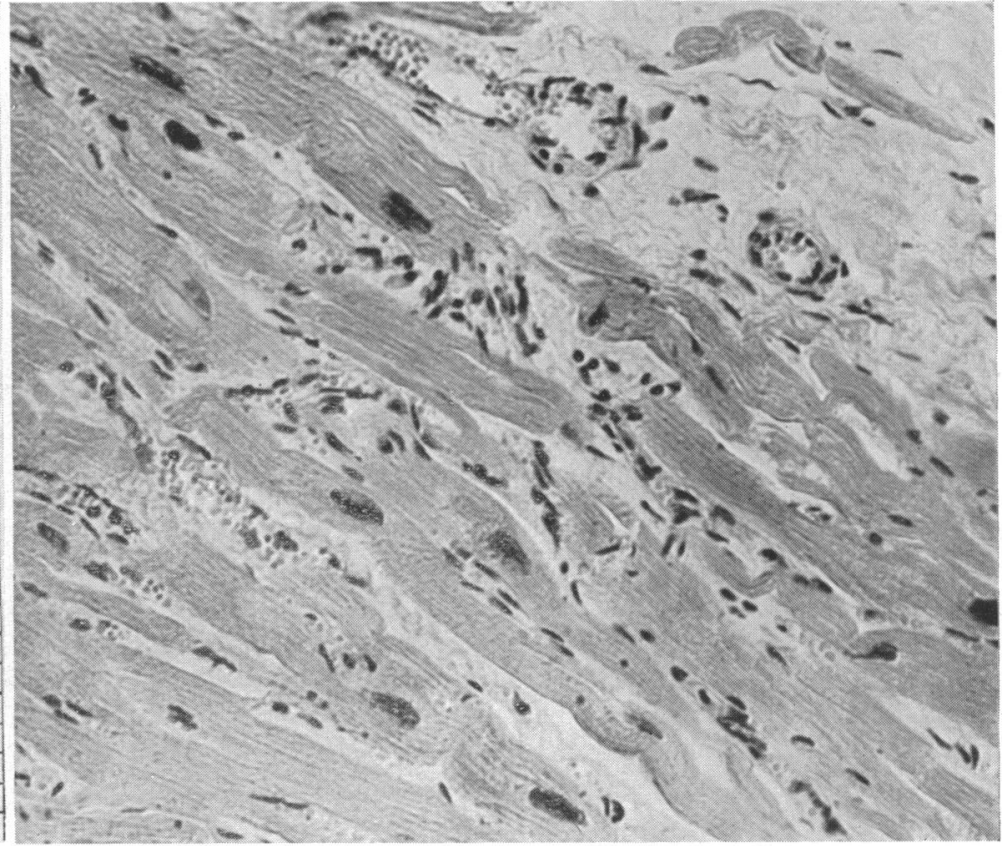

Fig. 2.-Microscopical section of the myocardium showing fibrosis, muscular hypertrophy, and cellular infiltrate. $\mathrm{H}$ and $\mathrm{E}, \times 1 / 290$.

No Aschoff bodies were seen. The sections were examined by Dr. C. V. Harrison of the Postgraduate Medical School, University of London, who reported: " This is an example of a smouldering, almost healed myocarditis. The fibrosis is not of the type or distribution which one sees in either rheumatism or ischæmia and there is endarteritis in small arteries and still some cellular infiltration in the interstitial tissue. The myocardial hypertrophy could, I think, be due simply to the long-continued myocardial failure resulting from the inflammatory myocarditis"

\section{Discussion}

It is reasonably clear that we are dealing with an instance of late isolated diffuse (Fieldler's) myocarditis (Saphir, 1942b). Whether this man really had rheumatic fever at the age of seven we do not know, but the present pathological findings are not those of rheumatism. Aschoff nodes are necessary to make the diagnosis in the absence of typical valvular lesions (Saphir, 1941 and 1942a). Pericardial adhesions may or may not be a cause of cardiomegaly (Wolfe, 1950), but were hardly sufficiently severe to have caused it here, in addition to which there is ample cause for both the adhesions and the cardiac enlargement in chronic inflammation. The Wassermann reaction is not 
available, but syphilis may be confidently excluded as the cause. Syphilitic myocarditis is very rare, is gummatous, and may only be diagnosed if typical gummata are found or treponemata demonstrated (Saphir, 1942a).

Whether there is any relationship between idiopathic hypertrophy and chronic myocarditis is at the moment a matter for conjecture. Some authors (Jones and Marshall, 1948; Ware and Chapman, 1947; Sellers and Phillips, 1946) have postulated that hypertrophy with fibrosis without cellular infiltrate may be the end result of a healed chronic myocardial inflammation. That the two may not always be easy to differentiate is well shown in a case report from the Massachusetts General Hospital (1951) though the microscopic findings may have been altered by cortisone therapy. It is more difficult to link up a familial history of heart disease with inflammatory findings, and little will be gained at present by speculation. A case report similar to this in many ways was published by Addarii et al. (1946) though the evidence of inflammation was very slight.

\section{Summary}

A case is reported that corresponds clinically and cardiographically to the syndrome of familial cardiomegaly, but had, at autopsy, the findings of a late isolated diffuse myocarditis.

I wish to thank Dr. G. L. S. Konstam for allowing me to record this case and Dr. Richard Pearce together with Dr. C. V. Harrison for their pathological reports. I am grateful to Mr. H. G. Blunt for providing slides and photographs.

\section{REFERENCES}

Addarii, F., Martini, L., Maheim, I., and Winston, M. (1946). Cardiologia, 11, 36. Case Records Massachusetts General Hospital (1951). New Engl. J. Med., 245, 107.

Evans, W. (1949). Brit. Heart J., 1, 68.

Jones, H. E., and Marshall, A. G. (1948). Arch. Dis. Child., 23, 201.

Saphir, O. (1941). Arch Path., 32, 1000.

, (1942a). Arch Path., 33, 88.

, (1942b). Amer. Heart J., 24, 167.

Sellers, A. L., and Phillips, E. (1946). Permenente Found. Med. Bull., 4, 24.

Ware, E. R., and Chapman, B. M. (1947). Amer. Heart J., 33, 530.

Wolfe, L. I. (1950). Permenente Found. Med. Bull., 8, 122. 